\title{
PERAN NEGARA DALAM PERUMUSAN KEBIJAKAN PENGENDALIAN TERORISME DI INDONESIA (Study Analisa Kriminologis)
}

\author{
Rudy Rudolf Valentino
}

\begin{abstract}
The tragedy of Bali Bombing in Legian-Kuta in October 12, 2002 brought the issue of terrorism to the forefront of Indonesia's security thinking. In Indonesia's counter terrorism policy, terrorism is defined as criminal act. This has been a long debate due to the ambiguities in the definition of terror and has produced multi-interpretation. People anxious this definition of terror interpreted freely by stakeholders. As a result,the ideal purpose of a policy could not be achieved, on the contrary it will produce a new problem that harms democracy. This research concludes that the state has played an important role to formulate Indonesia's counter terrorism strategy in Law Enforcement model in order to protect human rights in the democracy framework. However, this Law Enforcement model should be supported by the preventive measures which will be regulated under social policy to keep the coercive power and the persuasive power balance.
\end{abstract}

Keywords : Role of State, Counter Terrorism, Policy.

\begin{abstract}
ABSTRAK
Tragedi Bom Bali di Legian-Kuta pada 12 Oktober 2002 membawa isu terorisme ke garis depan pemikiran keamanan Indonesia. Dalam kebijakan anti-terorisme di Indonesia, terorisme didefinisikan sebagai tindak pidana. Ini telah menjadi perdebatan panjang karena ambiguitas dalam definisi teror dan telah menghasilkan multi-interpretasi. Terdapat kekhawatiran perbedaan definisi teror ini ditafsirkan secara bebas oleh para pemangku kepentingan. Akibatnya, tujuan ideal kebijakan tidak dapat dicapai, sebaliknya itu akan menghasilkan masalah baru yang merugikan demokrasi. Penelitian ini menyimpulkan bahwa negara telah memainkan peranan penting untuk merumuskan strategi kontra terorisme di Indonesia dalam model Penegakan Hukum untuk melindungi hak asasi manusia dalam rangka demokrasi. Namun, model yang Penegakan Hukum ini harus didukung oleh tindakan pencegahan yang akan diatur dalam kebijakan sosial untuk menjaga kekuasaan koersif dan keseimbangan kekuatan persuasif.
\end{abstract}

Kata kunci: Peran Negara, Counter Terrorism, Kebijakan

\section{PENDAHULUAN}

Terorisme di Indonesia bangkit kembali setelah "mati suri" selama puluhan tahun. Tragedi Bom Bali di Paddy's Pub dan Sari Club Jalan Legian-Kuta pada hari Sabtu tanggal 12 Oktober 2002 sekitar pukul 23.30 waktu setempat, merupakan titik tanda bahwa terorisme telah lahir kembali di bumi pertiwi. Tepat satu minggu pasca terjadinya Bom di Legian, KutaBali, pada hari Sabtu tanggal 19 Oktober 2002, Pemerintah Indonesia mengeluarkan Perppu No. 1 Tahun 2002 tentang Pemberantasan Tindak Pidana Terorisme yang diumumkan Menteri Kehakiman dan HAM Yusril Ihza Mahendra sebagai komitmen anti terorisme dan koalisi bersama masyarakat internasional dalam perang melawan terorisme (Keterangan Pemerintah, $2002: 8$ ).
Perppu ini dapat dikatakan abnormal karena dikeluarkan dalam keadaan darurat dan dalam kegentingan yang memaksa dengan merujuk Pasal 22 UUD 1945. Sebenarnya pemerintah sejak awal tahun 1999 telah mengambil langkah untuk menyusun RUU Tindak Pidana Terorisme sebagai langkah antisipatif untuk mencegah dan menanggulangi tindak pidana itu di tanah air (Keterangan Pemerintah, 2002 : 10).

Demi menyikapi situasi keamanan dan desakan dari dalam dan luar negeri, Perppu ini terpaksa lahir "prematur" sebagai respon resmi negara atas Tragedi di Legian, Kuta-Bali yang terjadi 6 (hari) sebelumnya. Mengingat masa berlaku suatu Perppu sangat terbatas, Perppu No. 1 Tahun 2002 ini kemudian ditetapkan menjadi UU No. 15 Tahun 2003 tentang Pemberantasan Tindak Pidana Terorisme pada tanggal 4 April 2003. Tidak ada perubahan substansi pada Perppu No. 1 Tahun 2002 setelah ditetapkan 
menjadi UU No. 15 Tahun 2003. Dengan kata lain, isi dari UU No. 15 Tahun 2003 adalah Perppu No. 1 Tahun 2002 (Hardiman et al., 2003 : 81-132).

\section{Terorisme Sebagai Dampak Krisis Multidimensi dan Global.}

Teror dapat dikatakan sebagai taktik atau metode dalam perang gerilya yang bertujuan melumpuhkan semangat tempur musuh melalui perang urat syaraf. Banyak ahli yang percaya bahwa dalam perang gerilya, yang dihancurkan bukan kekuatan bersenjata musuh tetapi kemauan atau semangat bertempur musuh. Dalam perang gerilya yang bermakna asimetrik, musuh tidak dihadapi head to head seperti pada perang konvensional. Taktik teror dikembangkan untuk buying time yang bertujuan mengulur waktu sampai semangat tempur musuh mengendor. Pada waktu lawan lengah para gerilyawan akan kembali melakukan serangan, demikian seterusnya sampai musuh frustasi dan kembali dengan kekalahan (Prabowo, 2012 : 188). Dalam rangka menciptakan kondisiketakutanuntuk mencapai kemenangan, para pelaku teror menggunakan metode sebagai berikut :

a. Penculikan dan penyanderaan (Kidnap and Hostage Taking).

Taktik teror sebenarnya sama dengan taktik yang digunakan pada sebuah operasi militer, salah satunya adalah penyanderaan (Abadinsky, 2007 : 7). Perbedaan antara penculikan dan penyanderaan dalam dunia terorisme sangat tipis. Penculik biasanya menahan target di tempat tersembunyi dan tuntutan utama biasanya berupa materi atau uang. Sedangkan penyanderaanbiasanyamenahan sandera di tempat umum dengan tuntutan lebih dari sekedar materi biasanyamerupakan tuntutanpolitik (Erickson, 1989).

b. Pembajakan (Hijack).

Pembajakan terhadap pesawat terbang komersial merupakan bentuk operasi yang sangat populer dan sering terjadi. Teror dengan metode ini pernah terjadi terhadap pesawat terbang DC-9 milik maskapai penerbangan Garuda Indonesia di bandara Don Muang, Thailand pada tahun $1981 \quad$ (id.wikipedia. org/wiki/read/3/1/2013). Bahkan tragedi penyerangan terhadap gedung World Trade Center-New York dan PentagonWashington DC pada tanggal 11
September 2001 juga mengadopsi bentuk operasi ini.

c. Pembunuhan (Assassination).

Pembunuhan adalah bentuk aksi teroris yang tertua dan masih digunakan hingga saat ini. Sasaran dari pembunuhan ini biasanya adalah pejabat pemerintah, penguasa, politisi dan aparat keamanan. Bentuk operasi ini menciptakan efek psikologis tersendiri. 4 (empat) orang presiden AS juga menjadi korban dari aksi teror bentuk ini yaitu Lincoln, Garfield, Mc Kinley dan Kennedy (Johnson, 1982 : 161).

d. Teror bom (Bombing).

Bom adalah jenis yang paling umum digunakan dalam aksi teror. Para pelaku teror dapat belajar merakit bom hanya dengan membaca dari internet dan buku panduan atau manual book serta dengan memanfaatkan bahan-bahan yang bisa diperoleh dengan mudah di pasaran. Di Indonesia aksi ini termasuk mengkhawatirkan karena sering terjadi (Wiliams, 2008).

e. Serbuan sporadis (Attack).

Serangan teror yang menggunakan teknik dan taktik gerilya yang dikombinasikan dengan taktik sporadis tidak banyak terjadi. Tapi apabila bentuk teror ini sampai terjadi maka dampak traumatis dan ketakutannya sangat luas. Aksi teror dengan metode ini pernah terjadi di Mumbai India pada tanggal 26 November 2008 yang dikenal dengan peristiwa Mumbai Attack (Journal of Terrorism Research, 2011 : 4-14)

f. Pembakaran (Arson).

Agak jarang didengar aksi teror yang mengadopsi metode ini sebagai taktik. Perbuatan ini dilakukan secara sengaja dengan membakar properti (Ronczkowski, 2004 : 39) dengan tujuan merusak hingga menimbulkan efek ketakutan yang luas dalam masyarakat. Teror dengan metode ini pernah dilakukan Kaisar Nero yang membakar kota Roma dalam sejarah Romawi (Ramraj et al., 2005 : 193).

g. Pengrusakan terhadap fasilitas umum (Sabotage).

Merusak fasilitas umum atau property damage dapat dikategorikan sebagai tindakan teror (Ronczkowski, 2004 : 39). Terlebih lagi ketika hal ini berkaitan dengan hajat hidup orang banyak. Misalnya sumber air minum yang diracun atau pengrusakan gardu listrik 
yang mengakibatkan kebakaran secara luas.

h. Perompak atau bajak laut (Piracy).

Sebetulnya perompakan juga merupakan aksi teror (Ronczkowski, 2004 : 40) hanya saja kurang mendapat perhatian karena tidak banyak memakan korban jiwa. Dalam aksi perompakan, sandera yang hidup lebih berharga daripada sandera yang mati. Sandera yang mati tidak akan mendapat pembayaran uang tebusan. Sehingga target dibiarkan hidup untuk nilai tukar yang tinggi (Journal of Terrorism Research, 2011: 27-36).

i. Perampokan (Robbery).

Aksi teror dengan bentuk ini agak sulit diidentifikasi sebagai aksi teror karena lebih dianggap sebagai tindak pidana umum. Yang membedakan hanyalah aspek motivasi dan tujuannya. Metode ini lebih dikenal dengan istilah $F a^{\prime} i$, yaitu merampok atau merampas harta dari lawan atau orang yang dianggap lawan untuk mendanai aksi teror selanjutnya (Purwanto, 2012 : 28).

j. Bioterorisme (Bioterrorism).

Bioterorisme ini merupakan senjata biologi yang relatif mudah dan murah untuk didapat serta dapat dengan mudah disebarkan, dampak ketakutan dan kepanikan yang ditimbulkan juga cepat meluas disamping kerusakan fisik yang terjadi (Forst, 2009 : 168).

k. Narkoterorisme (Narcoterrorism).

Terminologi narkoterorisme (Roth, 2010 : 57) sering digunakan untuk menggambarkan hubungan antar terorisme dan penjualan obat-obatan terlarang.Pendapat lain menerangkan bahwa narkoterorisme sengaja dilakukan sebagai upaya penggalangan dana bagi aksi teror suatu kelompok dengan memanfaatkan jalur perdagangan narkotika. Aksi teror juga dimanfaatkan sebagai instrumen untuk melindungi atau memperluas agenda politis serta tujuan ideologis atau sebaliknya (Forst, 2009 : 213).

1. Teror Dunia Maya (Cyberterrorism).

Cyberterrorism memiliki definisi yang sempit dan kontroversial sehingga sulit untuk mengidentifikasi keberadaannya. Tujuan Cyberterrorism dapat berupa tujuan politis atau ideologis (Forst, 2009 : 181). Bruce Hoffman mengatakan bahwa senjata dari para pejuang perang asimetris tidak hanya bom atau senjata yang kita kenal selama ini tapi juga handycam, videotape, televisi dan internet (Hoffman, $2006: 183-184$ )

\section{Lesson Learn dari Somalia.}

Kapal MV Sinar Kudus milik PT SamudraIndonesia (Persero)berbobot 8.911 ton dibajak perompak Somalia pada tanggal16 Maret 2011. Kapal ini membawa 20 (duapuluh) ABK dan mengangkutferonikel dengan tujuan Belanda. Ketika dibajak, MV Sinar Kudus berada di Perairan Somalia tepatnya di sekitar 350 mil laut tenggara Oman. Presiden segera menggelar rapat kabinet terbatas pada 18 Maret 2011 dan memutuskan untuk mengirim personel militerdengan sandi Duta Samudra I/2011.Dalam operasi pembebasan sandera ini dibentuk Satgas Merah Putih, yang merupakan Satuan Tugas TNI yang dibentuk secara khusus untuk menyelamatkan kapal berikut awak kapal. Personel yang dikerahkan terdiri atas pasukan khusus dari Kopassus, Marinir dan Kopaska. Operasi ini berlangsung selama 46 (empat puluh enam hari) dan berhasil menyelamatkan kapal MV Sinar Kudus serta membebaskan semua anak buah kapal (Pusat Penerangan Tentara Nasional Indonesia, 2012). Pembajakan dan penyanderaan kapal MV Sinar Kudus adalah sebuah pembelajaran bahwa aksi teror tidak hanya dilakukan dengan metode bom bunuh diri tapi juga dengan metode lain yang sama sekali tidak pernah diduga.Teror merupakan ancaman yang laten, bisa terjadi kapan saja, dimana saja dan terhadap siapa saja. Untuk itu dibutuhkan ketanggapan dan kesiapsiagaan yang prima agar fenomena ini dapat dideteksi, dicegah serta direspon secara cepat dan tepat. Peristiwa ini merupakan aksi teror yang luput dari kebijakan kontra teror dan perhatian BNPT sebagai badan kontra teror nasional. Memperhatikan konteks yang ada diatas dapat dilihat kebutuhan bagi pemerintah untuk menyusun Kebijakan Kontra Terorisme yang ideal dan lebih komprehensif sehingga pengendalian terorisme dapat dilakukan lebih terarah, sistematis dan terintegrasi.

\section{Kontra Terorisme Sebagai Kebijakan Negara.}

Sejak Perppu No. 1 Tahun 2002 resmi diundangkan, kendali aktivitas kontra terorisme berada pada Polri dalam hal ini Densus 88 . Sejauh ini aktivitas kontra terorisme di Indonesia telah berjalan dengan baik, dimana Polri cq Densus 88 berhasil mengungkap sejumlah kasus teror di tanah air. Masyarakat baik dari dalam maupun luar negeri banyak memberi apresiasi atas keberhasilan Polri yang bekerja keras dalam mengungkap jaringan teror di Indonesia. 
Tingginya apresiasi publik pada penumpasan teroris juga terekam pada jajak pendapat Kompas yang dilakukan antara 22-23 Juni 2011 dengan hasil sebanyak $60,7 \%$ responden puas terhadap kinerja polisi dalam hal menangani aksi teror. Meski angka ini menurun dibandingkan dengan tahun 2010, kepuasan publik terhadap penanganan aksi teror jauh lebih tinggi daripada penanganan kasus kejahatan lain seperti kejahatan kerah putih atau kejahatan jalanan (regional.kompas.com/read/2011/06/27).

Pada salah satu stasiun televisi swasta, Kepala BNPT Ansyaad Mbai menegaskan bahwa dunia internasional menjadikan Indonesia sebagai salah satu model penanggulangan terorisme di negara masing-masing. Hal itu berkat Indonesia dinilai berhasil oleh banyak negara dalam mencegah dan menanggulangi teroris dalam melakukan aksinya (nasional.tvonenews.tv/berita/ view/63090/2012/10/19).

Kepala BNPT Ansyaad Mbai dalam kegiatan Sarasehan Kamtibmas yang diselenggarakan Polda Jabar di Hotel HorizonBandung pada tanggal 4Juni 2013 menjelaskan bahwa strategi kontra terorisme Indonesia adalah Pencegahan, Penindakan, Kesiapsiagaandan Kerjasama Internasional. Dalam hal Penegakan Hukum terhadap terorisme, Polri telah mencapai keberhasilan dalam mengungkap semua kasus teror yang terjadi di Indonesia pada kurun waktu 10 (sepuluh) tahun dari tahun 2002-2012.

Tabel A. Data Keberhasilan Polri Dalam Kegiatan Kontra Terorisme Tahun 2002-2012.

\begin{tabular}{|c|c|c|}
\hline \multicolumn{3}{|c|}{ JUMLAH PELAKU TEROR } \\
\hline DITANGKAP & DISIDANG & BEBAS \\
\hline 810 & 500 & 300 \\
\hline
\end{tabular}

Sumber : Naskah Presentasi Ka BNPT, 4 Juni 2013.

Pendapat yang berbeda dari Sidney Jones bahwa Terorisme yang tadinya dilabel sebagai kejahatan telah berevolusi menjadi "pertempuran kecil" antara kelompok radikal dan polisi. Sidney Jones menyampaikan hal ini dalam sebuah pertemuan Jakarta Foreign Correspondents Club (Naskah Presentasi ICG dalam JFCC, 7 Februari 2013). Peristiwa ini tentu sangat menyedihkan dimana konflik yang terjadi telah menimbulkan korban jiwa dari kedua belah pihak. Telah terjadi violance reproduction pada fenomena ini, kekerasan hanya akan melahirkan kekerasan. Hal inilah yang mendasari pemikiran Jayne Mooney dan Jock Young bahwa Terrorism and Anti-
Terrorism Terrorism are Two Ways of Doing Evil (Mooney and Young, 2005).

Meskipun kemajuan sangat terlihat dalam upaya kontra terorisme, tapi gerakan ini tetap regenerasi dan mutasi menjadi gerakan bersenjata yang menjadikan pejabat pemerintah dan aparat keamanan sebagai target (lihat Tabel B). Apabila kita perhatikan beberapa aksi teror yang terjadi dalam 1 (satu) tahun terakhir, justru aparat kepolisian yang sedang bertugas menjadi sasaran para pelaku teror sebagai aksi balas dendam seperti yang terjadi di Solo (antaranews.com/berita/330667/2012/12/21) dan Poso (nasional.kompas.com/read /2012/12/21).

Tabel B. Daftar Polisi dan TerdugaTeroris Yang Meninggal Pada Periode 2002-2012

\begin{tabular}{|c|c|c|c|}
\hline \multirow{2}{*}{ NO } & \multirow{2}{*}{ TAHUN } & \multicolumn{2}{|c|}{ KORBAN MENINGGAL } \\
\cline { 3 - 4 } & & TERDUGA TERORIS & POLISI \\
\hline 1. & 2002 & 0 & 0 \\
\hline 2. & 2003 & 0 & 0 \\
\hline 3. & 2004 & 0 & 0 \\
\hline 4. & 2005 & 4 & 5 \\
\hline 5. & 2006 & 3 & 1 \\
\hline 6. & 2007 & 16 & 1 \\
\hline
\end{tabular}




\begin{tabular}{|c|c|c|c|}
\hline 7. & 2008 & 0 & 0 \\
\hline 8. & 2009 & 9 & 0 \\
\hline 9. & 2010 & 28 & 10 \\
\hline 10. & 2011 & 4 & 3 \\
\hline 11. & 2012 & 11 & 8 \\
\hline 12. & 2013 & 7 & 0 \\
\hline \multicolumn{2}{|c|}{ T O T A L } & 90 & 28 \\
\hline
\end{tabular}

Sumber : Naskah Presentasi ICG pada JFCC, 7 Februari 2013.

Soerjono Soekanto dalam bukunya Sosiologi Suatu Pengantar mengatakan bahwa suatu norma dikatakan melembaga ketika norma tersebut diketahui, dipahami, ditaati dan dihargai (Soekanto, 2007 : 177). Peristiwa ini merupakan pelajaran yang sangat berharga dimana norma hukum sudah tidak dihargai, baik oleh kelompok radikal maupun oleh aparat penegak hukum.

Terorisme tidak surut setelah bertempur selama puluhan tahun sejak awal berdirinya NKRI. Pelaku teror dapat ditangkap atau dibunuh, tetapi keyakinannya tidak mudah untuk ditaklukkan (Hendropriyono, 2009 : vii). Pada Seminar Metamorfosa Terorisme di PTIK, Deputi Penindakan BNPT Arif Darmawan menjelaskan bahwa tujuan dan bentuk organisasi teror sudah bertransformasi dan menggunakan strategi acak tanpa koneksi internasional (Naskah Presentasi Deputi Penindakan BNPT, 11 September 2013).

Tabel C. Data Pelaku Teror 2002-2013 per tanggal 20 Agustus 2013.

\begin{tabular}{|c|c|c|c|c|c|}
\hline \multicolumn{7}{|c|}{ JUMLAH PELAKU TEROR } \\
\hline DITANGKAP & $\begin{array}{c}\text { MENINGGAL } \\
\text { DI TKP }\end{array}$ & $\begin{array}{c}\text { BOM BUNUH } \\
\text { DIRI }\end{array}$ & $\begin{array}{c}\text { HUKUMAN } \\
\text { MATI }\end{array}$ & BEBAS & $\begin{array}{c}\text { DALAM } \\
\text { PROSES }\end{array}$ \\
\hline 904 & 103 & 12 & 3 & 73 & 85 \\
\hline
\end{tabular}

Sumber : Naskah Presentasi Deputi Penindakan BNPT, 11 September 2013.

Memperhatikan $10 \quad$ (sepuluh) tahun keberadaan kebijakan kriminal pemberantasan tindak pidana terorisme dan baiknya performa penegakan hukum terhadap terorisme di Indonesia, pertanyaan kritis yang muncul adalah "apakah Indonesia sudah berada pada posisi aman dari ancaman terorisme?"

Berdasarkan beberapa data diatas dapat dilihat bahwa strategi kontra terorisme masih terbatas pada body count yaitu berapa banyak teroris yang berhasil ditangkap atau dibunuh, namun tidak pada upaya pencegahan sistemik melalui suatu mekanisme kontrol sosial. Kebijakan Kriminal Pemberantasan Tindak Pidana Terorisme ini belum mengadopsi adagium "Mencegah lebih baik daripada Mengobati". Kebijakan ini lebih merepresentasikan suatu tindakan represif berupa penegakan hukum daripada upaya preventif berupa upaya mengenali kelompok rentan, deteksi dini, cegah dini dan tindak dini. Kelemahan yang paling mendasar dalam kebijakan tersebut adalah tujuan strategisnya.
Adanya simplifikasi permasalahan dalam kasus ini seolah terorisme di Indonesia dapat diselesaikan hanya dengan mekanisme peradilan pidana. Strategi kontra teror ini masih menggunakan pendekatan one size fits for all (Fenstermacher et al., 2010: 7) dan belum memberi perhatian pada kompleksnya akar masalah yang dapat melahirkan aksi teror. Induk pasukan para pelaku teror ini tetap berada pada posisi yang aman, misterius dan belum tersentuh. Akibatnya teror masih tetap ada dan menjadi ancaman terhadap keamanan dan ketertiban bahkan dalam skala besar dapat mengganggu stabilitas nasional dan kedaulatan negara.

Ancaman dan pola aksi para pelaku teror ini juga mendapat perhatian serius dari pemerintah Australia yang merupakan negara tetangga Indonesia dengan menyebutkan bahwa walaupun figur para pemimpin jaringan teror dunia sudah dapat ditangkap, diadili dan dieksekusi bahkan tewas dalam pertempuran tapi para pelaku teror ini memiliki kapasitas untuk melakukan 
regenerasi dengan cepat (Australia CounterTerrorism White Paper, 2010 : 11).

Lesson learn yang bisa dipetik dari 10 (sepuluh) tahun peristiwa teror ini adalah bahwa penegakan hukum yang sejatinya adalah pendekatan koersif tidak bisa berjalan sendiri. Untuk itu perlu dipikirkan strategi alternatif berupa non-lethal measures untuk mendukung penegakan hukum yang telah dilakukan. Ami Angell dan Rohan Gunaratna berpendapat bahwa penanggulangan atau penanganan terhadap aksi teror dengan hanya menggunakan hard line approach tidak mendatangkan hasil sesuai yang diinginkan. Kita bisa saja melakukan perang melawan terorisme dengan menangkap, menghukum, atau bahkan membunuh para pelaku, namun strategi ini tidak dapat sepenuhnya memenangkan pertarungan. Untuk itu diperlukan strategi yang lebih baik dan lebih tepat melalui upaya yang bersifat preventif berupa mengenali kelompok rentan, membangun ikatan sosial dengan masyarakat dan membentuk rehabilitasi terpidana teror melalui proses reintegrasi ke dalam masyarakat (Angell dan Gunaratna, 2012 : 349).

\section{PEMBAHASAN}

\section{Kebijakan Kontra Terorisme Sebagai Hegemoni Negara}

Kontra terorisme di Indonesia dalam kenyataan tampak tersendat-sendat dan diwarnai sejumlah pelanggaran, sehingga menimbulkan citra negatif terhadap aparat penegak hukum secara khusus dan pemerintah secara umum.Padahal negara sudah berjuang keras bahkan sampai kehilangan abdi terbaiknya dalam penugasan (lihat Tabel B). Pendekatan legalistik yang berorientasi pada penindakanatau represi hanya dapat dilakukan kasus per kasus dan tidak berlaku universal dalam jangka panjang. Untuk itu diperlukan pendekatan dan kebijakan komprehensif secara keilmuan diluar pendekatan hukum seperti pendekatan sosial, budaya, agama, ekonomi, pendidikan dan kesejahteraan dalam penyelenggaraan negara.

Dengan kebijakan yang bersifat komprehensif diharapkan ditemukan solusi dalam pencegahan danpenanggulangan terorisme yang lebih optimal dan efektif.Pandangan tentang perbedaan antara teoritis dan empiris mengandung kebenaran namun bersifat relatif dan terkadang bersifat subyektif. Namun demikian adanya pandangan tersebut tidak berarti bahwa perbedaan tidak dapat diatasi atau didekatkan karena pengalaman yang benar sering memerlukan juga perubahan-perubahan terhadap teori-teori yang telah dibangun sebelumnya.

Salah satu pendekatan yang dilakukan adalah melalui Teori Hegemoni Antonio Gramsci. Sebenarnya teori ini adalah teori ilmu politik yang diadopsi oleh ilmu sosial. Pada ilmu pengetahuan modern dimana batas ilmu pengetahuan sudah sulit dipisahkan secara tegas, diharapkan teori ini mampu menegaskan peran negara dalam melakukan distribusi dan separasi kekuasaan melalui kebijakan. Dalam buku Prison Notebooks Antonio Gramsci menerangkan bahwa politik realistik tidak perlu memusatkan perhatian hanya pada kesuksesan yang seketika. Apabila negara berfokus pada kesuksesan yang seketika, maka negara akan berupaya menciptakan kesuksesan itu dengan berbagai cara. Yang paling mungkin dan paling cepat untuk dilakukan adalah repressive movement dengan menggunakan perangkat koersif. Dalam political order yang direpresentasikan dengan adanya sistem parlementer, hal ini hanya bisa dicapai melalui perangkat perjuangan dan pengerahan massa dalam jumlah yang besar, yang diasumsikan sebagai pelibatan peran serta masyarakat, baru kemudian ketertiban politis dapat tercipta (Buttigieg, 1996 : 60-61).

Pada teori hegemoni Gramsciditerangkan bahwa negara memiliki 2 (dua) perangkat kerja yang dapat menjadi instrumen kontra terorismeyaitu Coercive Power danPersuasive Power. Yang sudah dilakukan pemerintah saat ini dan sangat dominan adalah pendekatan Coercive Power. Ercan Gündoğan dari Universum University College, Pristine, Kosovo menyebut pendekatan Persuasive Powersebagai the role of intellectuals in the organisation of hegemony (Gündoğan, 2008 : 46). Sangatlah bijaksana apabila negara juga menggunakan perangkat persuasifnya untuk mendampingi perangkat koersifnya dalam menghadapi terorisme.

\section{Rekonstruksi Makna Teror Dalam Kebijakan}

Pemikiran kriminologi konstitutif merupakan pemikiran kriminologi kritis yang matang, yang memahami kejahatan dengan mempertimbangkan hasil akhir dari wacana yang dilakukan manusia dalam mempertahanan ideologi bahwa kejahatan adalah realitas yang kongkret (Mustofa, 2010 : 60). Berangkat dari pemikiran tersebut bahwa dalam memahami terorisme harus mempertimbangkan hasil akhir dari wacana dimana terorisme merupakan 
realitas yang abstrak. Dapat dilihat dalam Undang-Undang Nomor 15 Tahun 2003 tentang Pemberantasan Tindak Pidana Terorisme, makna teror dan terorisme itu tidak ada.

Premis pertama dari kriminologi konstitutif adalah codeterminationof crime as ideology (Henry and Milovanovic,1991 : 295), bahwa perumusan definisi kejahatan yang dilakukan secara bersama merupakan jiwa dan pandangan hidup kriminologi konstitutif. Pada konteks teror di Indonesia kriminalisasi terhadap perilaku teror telah disepakati bersama melalui praktek kewacanaan yang merupakan premis kedua dari kriminologi konstitutif.

Premis kedua discurssive practice as medium of codetermination(Henry and Milovanovic, 1991 : 299) memiliki pengertian bahwa dalam melakukan rekonstuksi makna ini diperlukan praktek kewacanaan yang akan menggiring konstruksi sosial terhadap makna teror ini. Praktek kewacanaan ini dapat dilakukan dalam berbagai macam kegiatan seperti sosialisasi, seminar, FGD atau pertemuan lain yang bersifat konstruksi wacana teror didalam masyarakat.

Premis ketiga simbolic violance as ideological domination (Henry and Milovanovic,1991 : 303), yaitu kekerasan simbolis sebagai dominasi ideologis. Bahwa terorisme merupakan kekerasan simbolis dimana pelaku teror ini tidak menyerang target yang merupakan musuh sebenarnya tapi simbol yang merepresentasikan musuh agar dapat berkomunikasi dan melakukan dominasi terhadap sasaran utama.

Premis keempat adalah sense of data and meaning construction (Henry and Milovanovic,1991 : 305), artinya kita dapat mengkonstruksi makna berdasarkan realitas kongkret yang ada di sekitar kita dan kita alami sehari-hari. Di Indonesia, teror dan terorisme ini sudah dikenal sejak berdirinya NKRI. Terdapat kelompok teror domestik yang dikenal dengan homegrown terrorism yaitu NII dan kelompok teror kelas dunia atau antar negara yang dikenal dengan international terrorism yaitu JI.

Pelaku teror bermotivasi ideologis merasa diri mereka sebagai holy warriors ini merupakan produksi bersama atau coproduction (Supatmidan Sari, 2007 : 133) yang terjadi ketika human agent dengan melakukan suatu tindak kejahatan pada saat yang bersamaan dimana sebagian orang sedang berusaha melakukan pengendalian kejahatan dan mempelajari kejahatan. Akibatnya energi yang berlebihan terkumpul pada pelaku teror dan melegitimasi tindakannya bahwa perbuatan dan hasil perbuatannya adalah hal yang kongkret. Pelaku teror bertindak sebagai holy warriors dan dijanjikan mati syahid kemudian masuk surga disambut para bidadari.

Kriminologi Konstitutif tidak mencari penyebab terjadinya kejahatan, melainkan menguji hubungan di dalam masyarakat yang memproduksi kejahatan. Kemudian Kriminologi Konstitutif melakukan intervensi untuk mengurangi kerugian dan derita yang dihasilkan coproduction tersebut. Mengurangi kejahatan hanya akan terjadi dengan menurunkan investasi energi oleh agen manusia dalam ideologi produksi kejahatan.

Kebijakan kontra teror yang ada di Indonesia saat ini, melakukan kriminalisasi terhadap terorisme, artinya terorisme didefinisikan sebagai tindak pidana. Berdasarkan data yang diperoleh bahwa terorisme juga dapat muncul dalam berbagai manifestasi. Terorisme dapat muncul dalam bentuk ancaman terhadap kedaulatan. Terorisme sebagai ancaman dapat terjadi secara sporadis, sistematis dan masif akan menciptakan perang asimetrik dimana hal ini akan menjadi domain TNI. Terorisme dapat pula muncul dalam dimensi ideologis yang akan menjadi domain Kementerian Agama atau dimensi budaya yang akan menjadi domain Kementerian Pendidikan.

\section{KESIMPULAN DAN SARAN}

Mengingat terorisme merupakan permasalahan yang kompleks, multidimensi dan berevolusi sesuai perkembangan jaman, terorisme muncul dalam bentuk ancaman terhadap kedaulatan negara dan kejahatan luar biasa, untuk itu teror memerlukan perhatian yang khususdan respon terbaik dari pemerintah.

a. Perlu adanya rekonstruksi makna teror dan terorisme pada kebijakan kontra teror Indonesia untuk mendapatkan strategi yang lebih baik dan lebih komprehensif. Redefinisi makna teror ini akan sangat bermanfaat terhadap reposisi dan penyelarasan badan kontra teror nasional dalam hubungan dan tata cara kerja internal dan eksternal.

b. Semua Legislasi yang berkaitan dengan teror dan terorisme agar dikodifikasi untuk menghindari tumpang tindih dan perbedaan interpretasi. Persepsi yang ada dalam 
masyarakat terhadap kebijakan kontra teror nasional adalah bahwa negara tidak berpihak pada esensi dan harapan dari individu dan kelompok masyarakat.

c. Menyikapi terorisme yang berevolusi mengikuti perkembangan jaman dan tehnologi, harus ditemukan strategi pengendalian yang efektif dan efesien. Strategi yang digunakan haruslah lentur agar dapat segera beradaptasi terhadap perubahan baik secara taktis maupun strategis.

d. Indonesia perlu memiliki sistem manajemen kontra teror yang tidak hanya terfokus pada teror bom dan ideologi radikal berbasis agama. Masih banyak metode teror yang diadopsi oleh kelompok teror non-religi dan hal ini perlu diantisipasi oleh negara dalam rangka melindungi segenap bangsa dan seluruh tumpah darah Indonesia sesuai amanat konstitusi.

e. Negara tidak dapat bekerja sendiri dalam pemberantasan terorisme. Untuk itu diperlukan adanya konstruksi sosial terhadap bahaya terorisme sehingga masyarakat mengetahui dan memahami bahaya yang ditimbulkan. Konstruksi sosial ini dilakukan dalam rangka mengumpulkan kekuatan dan sumber daya dari masyarakat untuk menciptakan peran masyarakat pada deteksi dini, cegah dini dan deteksi dini yang merupakan bagian dari early warning system dan strategi kontra teror berbasis masyarakat. Masyarakat harus menjadi mitra terdekat negara dalam upaya untuk membuat strategi pemberantasan terorisme benar-benar komprehensif dan multidimensional.

f. Diperlukan adanya pengawasan, pengendalian, analisa dan evaluasi terhadap pelaksanaan program kerja dan anggaranbadan kontra teror nasional yang dilakukan secara periodik untuk menciptakan good governance yang transparan, kredibel dan akuntabel sebagai wujud dari negara demokrasi.

\section{DAFTAR PUSTAKA}

\section{Buku}

Abadinsky, Howard. (2007). Organized Crime, Ninth Edition, St. John's University, Wadsworth, Cengage Learning Australia,
Brazil, Japan, Korea, Mexico, Singapore, Spain, United Kingdom, United States.

Angell, Ami and Gunaratna, Rohan. (2012). Terrorist Rehabilitation The U.S.Experience in Iraq, CRC Press Taylor \& Francis Group, Boca Raton, London, New York.

Buttigieg, Joseph A. (1996). Antonio Gramsci Prison Notebooks, Volume II, Columbia University Press, New York.

Counter-Terrorism White Paper. (2010),Securing Australia, Protecting Our Community, Department of Prime Minister and Cabinet, Australia Government.

Erickson, Richard J. (1989). Legitimate Use of Military Force Against State Sponsored International Terrorism, Air University PressMaxwell Air Force Base, Alabama.

Fenstermacher et al., Laurie.(2010).Protecting the Homeland from International and Domestic Terrorism Threats, CounterTerrorismWhite Paper.

Forst, Brian. (2009).Terrorism, Crime, and Public Policy, Cambridge University Press, New York.

Hardiman et al., F. Budi. (2003). Terorisme : Definisi, Aksi dan Regulasi, Imparsial, Jakarta.

Hendropriyono, AM. (2009). Terorisme, Fundamentalis Kristen, Yahudi, Islam, Penerbit Buku Kompas, Jakarta.

Hoffman, Bruce. (2006).Inside Terrorism, Columbia University Press, New York.

Johnson, Chalmers. (1982).Revolutionary Change, Second Edition, Stanford University Press, California.

Mustofa, Muhamad. (2010). Kriminologi : Kajian Sosiologis Terhadap Kejahatan, Perilaku Menyimpang dan Pelanggaran Hukum, Edisi Kedua, Sari Ilmu Pratama, Bekasi.

Prabowo, JS. (2012). TNI Dalam Menyikapi Perubahan Lingkungan Strategis.

Purwanto, Wawan H. (2012). Satu Dasawarsa Terorisme di Indonesia, CMB Press, Jakarta. 
Pusat Penerangan Tentara Nasional Indonesia. (2012). Long Range Projection : Operasi Militer Merah Putih di Somalia,Markas Besar Tentara Nasional Indonesia, Cilangkap, Jakarta.

Ramraj et al., Victor V. (2005).Global AntiTerrorism Law and Policy, Cambridge University Press, New York.

Ronczkowski, Michael. (2004). Terrorism and Organized Hate Crime : Intelligence Gathering, Analysis and Investigations, CRC Press LLC, Boca Raton London New York Washington, D.C.

Roth, Mitchel P. (2010). Global Organized Crime, ABC-CLIO, LLC, Santa Barbara, California.Soekanto, Soerjono. (2007). Sosiologi Suatu Pengantar, Raja Grafindo Persada Jakarta.

Supatmi, MamiekSridan Sari, Herlina Permata. (2007). Dasar-Dasar Teori Sosial Kejahatan, PTIK Press, Jakarta.

Wiliams, Paul D. (2008). Security Studies : An introduction, Routledge, New York.

\section{Jurnal}

Gündoğan, Ercan. (2008). Conceptions of Hegemony in Antonio Gramsci's Southern Question and the Prison Notebooks, New Proposals : Journal of Marxism and Interdisciplinary Inquiry, Volume 2, No. 1, pp. 45-60 Universum University College, Pristine, Kosovo.

Henry, Stuart and Milovanovic, Dragan. (1991). Constitutive Criminology : The Maturation of Critical Theory, Criminology Volume 29 Number. 2, pp 293-316.

Journal of Terrorism Research. (2011). Volume 2, Issue 2, November 2011, University of St. Andrews.

Mooney, Jayne and Young, Jock. (2005). Imagining Terrorism : Terrorism and AntiTerrorism Terrorism, Two Ways of Doing Evil, Social Justice Volume : 32, No. 1 (2005), ProQuest Sociology pp. 113-125.

\section{Naskah Presentasi}

Naskah Presentasi Kepala BNPT dalam Kegiatan Sarasehan Kamtibmas : Mencegah dan Menanggulangi Radikalisme dan Terorisme di Jawa Barat yang diselenggarakan Polda Jabar di Hotel Horizon Bandung pada tanggal 4 Juni 2013.

Naskah Presentasi Deputi Penindakan BNPT dalam Seminar Metamorfosa Terorisme di Indonesia yang diselenggarakan PTIK Jakarta pada tanggal 11 September 2013.

Naskah Presentasi Sidney Jones, International Crisis Group, 7 February 2013, Getting Into MIT, Jakarta Foreign Correspondents Club.

Keterangan Pemerintah tentang diterbitkannya Peraturan Pemerintah Pengganti UndangUndang Nomor 1 Tahun 2002 tentang Pemberantasan Tindak Pidana Terorisme oleh Menkehham RI atas nama Pemerintah RI tanggal18 Oktober 2002.

\section{Website}

Apresiasi Penanganan Terorisme

http://regional.kompas.com/read/2011/06/27/020 95012/Apresiasi.Penanganan. Terorismediaks es pada hari Sabtu tanggal 22 Desember 2012.

BNPT : Indonesia Jadi Model Penanganan Terorisme

http://nasional.tvonenews.tv/berita/view/63090/2 012/10/19/bnpt_indonesia_jadi_model_penan ganan_terorisme.tvOnediakses pada hari Sabtu tanggal 22 Desember 2012.

Garuda Indonesia Penerbangan 206 Pasca Peristiwa Pembajakan

http://id.wikipedia.org/wiki/Garuda_Indonesia_P enerbangan_206\#Pasca_peristiwa_pembajaka ndiakses pada hari Kamis tanggal 3 Januari 2013.

Kelompok Baru Dalam Aksi Teror di Solo

http://www.antaranews.com/berita/330667/kelo mpok-baru-dalam-aksi-teror-di-solodiakses pada hari Senin tanggal 24 Desember 2012.

Ungkap Aksi Teror di Poso Terkendala Medan Berat

nasional.kompas.com/read/2012/12/21/13591421 /Ungkap.Aksi.Teror.di.Poso.Terkendala.Med an.Beratdiakses pada hari Senin tanggal 24 Desember 2012. 